\title{
Nickel Nanoparticle-Modified Electrode for the Electrochemical Sensory Detection of Penicillin G in Bovine Milk Samples
}

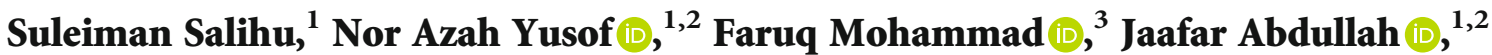 \\ and Hamad A. Al-Lohedan $\mathbb{1 0}^{3}$ \\ ${ }^{1}$ Department of Chemistry, Faculty of Science, Universiti Putra Malaysia, 43400 Serdang, Selangor, Malaysia \\ ${ }^{2}$ Institute of Advanced Technology, Universiti Putra Malaysia, 43400 Serdang, Selangor, Malaysia \\ ${ }^{3}$ Department of Chemistry, College of Science, King Saud University, Riyadh, 11451, Saudi Arabia
}

Correspondence should be addressed to Nor Azah Yusof; azahy@upm.edu.my and Faruq Mohammad; fmohammad@ksu.edu.sa

Received 20 August 2019; Revised 14 October 2019; Accepted 29 October 2019; Published 26 November 2019

Academic Editor: Ilaria Armentano

Copyright (c) 2019 Suleiman Salihu et al. This is an open access article distributed under the Creative Commons Attribution License, which permits unrestricted use, distribution, and reproduction in any medium, provided the original work is properly cited.

\begin{abstract}
The monitoring of chemical and antibiotic residues like amoxicillin, penicillin, tetracycline, and vancomycin in the food originating from the animal and plant sources can prevent the humans from getting exposed to the antibiotic-induced allergic reactions and also decreased immunity towards the microbial population. By taking into consideration the necessity of developing effective and sensitive techniques for milk containing Penicillin G antibiotics in an easy and cost-effective mode, the present work deals with the electrochemical sensor made up of nickel nanoparticles (NiNPs). In order to enhance the chemical stability and biocompatibility, the NiNPs were crosslinked with (3-aminopropyl)triethoxysilane (APTES) and the formed composite was thoroughly characterized using the physical characterization techniques. In addition, the qualitative analysis results confirmed the nanocomposite's synergetic effect towards the oxidation of Penicillin G. Further, the quantitative analysis towards the use of a nanocomposite electrode due to the changes in $\mathrm{pH}$, scan rate, accumulation time and potential, nanoparticle (NP) amount, etc. was optimized. The limit of detection and limit of quantitation of Penicillin $\mathrm{G}$ with this composite were detected to be $0.00031 \mu \mathrm{M}$ and $0.00100 \mu \mathrm{M}$, respectively. Overall, from the results, it can be indicated that the fabricated NiNP sensor can find its applications as a potential electrode material for the qualitative and quantitative analysis of Penicillin $\mathrm{G}$ in liquid samples.
\end{abstract}

\section{Introduction}

Penicillin G (benzylpenicillin) is an antibiotic commonly used for the treatment of bacterial infections in humans and animals where a substantial increase in the amount of this drug at trace levels in the samples of edible meat, dairy products, blood, and urine (from nanograms to micrograms per liter) in recent years has been a concern to the regulatory agencies. Penicillin $\mathrm{G}$ as shown in Figure 1 has a molecular formula of $\mathrm{C}_{16} \mathrm{H}_{18} \mathrm{~N}_{2} \mathrm{O}_{4} \mathrm{~S}$ that corresponds to the molecular weight of $334.4 \mathrm{~g} / \mathrm{mol}$. The wider application of penicillin as a medicine is due to its active pharmacological effects that can cure the bacterial infections like pneumonia, diphtheria, leptospirosis, strep throat, and gas gangrene. Because of the wider therapeutic uses of this drug in both humans and farm animals, it has been produced by many biotechnology, drug, and cosmetic industries where the critical step involves the purification, and if anything is done wrong, it will end up in water and soil contamination [1-3]. The wider application of penicillin as a direct medicine or unhindered utilization (meat, milk, and eggs) in both humans and farm animals is responsible for many negative effects like proliferation of drug-resistant bacteria and drug-involved hypersensitization (fever, urticaria, rashes, and joint pains) [4-6]. Hence, controlling the amount of the penicillin drug in food, milk, meat, and water samples is of utmost importance where many different instrumental techniques are involved for the qualitative and quantitative analysis.

With regard to penicillin adulteration, there have been a number of reports which confirm the presence of this drug in food, meat, milk, and water samples, and the major concern is that this amount is getting raised each year. These 


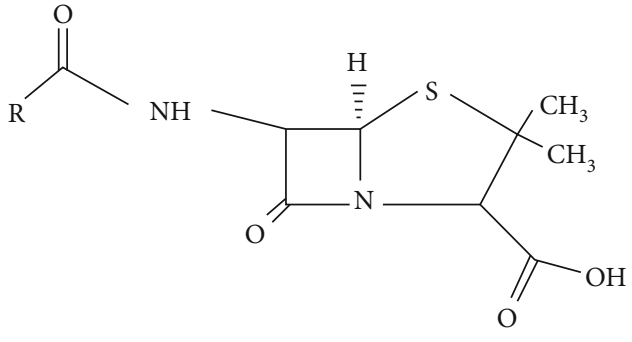

Figure 1: Chemical structure of Penicillin G.

multiple routes and associated increase in the amounts of Penicillin G or its degradation products in the wastewater have raised a substantial concern in the public and regulatory agencies since these have a significant effect to the human and ecological health. Since the byproducts of Penicillin G are associated with some potential risks to the humans and wildlife if they enter into the food and water cycle, the detection of Penicillin G has likely become more significant to protect the environment and human health. The commonly used techniques for the detection of Penicillin $G$ in samples are instrumental [7], such as capillary electrophoresis [8,9], gas chromatography $[10,11]$, liquid chromatography [11, 12] coupled with mass spectrometry [13], Fenton's process [14-16], UV/ZnO photocatalytic process [17], and some advanced oxidation processes [18]. However, each method has its own limitations like the requirement of skilled technicians, complex instruments, expensive method development, time-consuming process, unpredictable analysis time, usage of toxic solvents, and multiple washing steps, thereby making a strong need for the development of novel techniques with minimum of these limitations $[19,20]$. In that view, the electrochemical-based sensory methods proved to be interesting candidates and also low-cost alternatives for the biomolecular detection in liquid samples, since the electrochemical sensors can provide quick results and it is possible to miniature these devices to portable sizes that can trace even very low levels of Penicillin G where the sensitivity has not to be compromised. In that way, the electrochemical sensory detection of Penicillin G, therefore, is extrapolated from the electrochemical sensory technique in milk samples where the method involves the detection of current by making use of the simultaneous oxidoreduction process occurring at the electrode surface.

In recent years, the engagement of electrode materials with enriched electrochemical properties in many different electrolytes, physicochemical and thermal stabilities, and small background currents made them a fashionable choice in the analytical chemistry field for the qualitative and quantitative analysis [21], since a majority of commonly used electrode materials like mercury, lead, arsenic, and cadmium are unsuitable for such analytical applications because of their intrinsic toxicity, aggressive nature, chemical instability, and high costs. Interestingly, the nickel nanoparticles (NiNPs) offer some of the unique properties which make this material overcome the problems of affordability (not expensive like $\mathrm{Pt}, \mathrm{Pd}$, or $\mathrm{Ag}$ ), instability (characteristics are similar to noble metals), and toxicity (not aggressive as compared to $\mathrm{Hg}^{2+}, \mathrm{As}^{3+}, \mathrm{Pb}^{2+}$, and $\mathrm{Cd}^{2+}$ ) and maintains oxidoreductive properties. The screen-printed carbon electrodes (SPCE) have shown very promising results in the field of electroanalysis [22-24], and so, by taking advantage of its effective nature, the present work is aimed at evaluating the effectiveness of NiNP-modified SPCE for the electrodeposition of Penicillin G using an electrooxidation method. The formed composite was characterized thoroughly using different instrumental methods, and further, the effect of various physicochemical parameters towards the detection of Penicillin G in milk samples was evaluated.

\section{Materials and Methods}

2.1. Chemicals and Supplies. All the chemicals were used of the highest analytical reagent grades; reagents and solvents used in this study were purchased from a company (Finn Chemicals Sdn Bhd, Malaysia) and used without further purification. Penicillin G ((2S,5R,6R)-3,3-dimethyl-7-oxo-6-(2-phenylacetamido)-4-thia-1-azabicyclo[3.2.0]heptane-2-carboxylic acid) is reagent grade and was obtained from Fluka (Ronkonkoma, NY, USA). Polyvinylpyrrolidone (PVP) was purchased from R\&M Chemicals (Essex, UK), while nickel(II) chloride and (3-aminopropyl)triethoxysilane (APTES) were from SigmaAldrich (St. Louis, MO, USA). Deionized water was obtained from a Millipore water purification system. Phosphatebuffered solution (PBS) was prepared in a usual way. A stock solution of $0.01 \mathrm{~mol} / \mathrm{L}$ Penicillin G was prepared by dissolving $0.384 \mathrm{~g}$ Penicillin $\mathrm{G}$ sodium salt of the pure substance in a $100 \mathrm{~mL}$ volumetric flask with deionized water. More diluted solutions of penicillin were prepared by precise dilution of stock solutions. All glassware was washed and rinsed several times with deionized water.

2.2. Instrumentation. In this study, the electrochemical measurements were recorded using the potentiostat Metrohm ${ }^{@} \mu$ Autolab type III (Eco Chemie, Utrecht, The Netherlands) which was integrated with a screen-printed junction cable and is controlled by the NOVA 1.11 software. The SPCE was obtained from DropSens company (Oviedo, Spain), and the disk-shaped working electrode has a diameter of $4 \mathrm{~mm}$; the working and auxiliary electrodes were made of gold, while the reference electrode was made of silver. All the electrodes used for this study were printed on a ceramic support $(L 33 \times W 10 \times H 0.5 \mathrm{~mm})$, and the studies were done at room temperature conditions only. The DropSens potentiostat $\mu$ Stat 8000 electrochemical system connected to PC and the SPCE made of a three-electrode system, i.e., working electrode, counter electrode, and $\mathrm{Ag} / \mathrm{AgCl}$ reference electrode, was used. The electrochemical cell consists of a SPCE inserted in a glass medium mounted on a stirrer containing supporting electrolyte and analyte (Rapid Labs Sdn Bhd, Malaysia); a $\mathrm{pH}$ meter was used to adjust the $\mathrm{pH}$ of solutions while centrifugation was performed on a Kubota centrifuge (Japan). The Malvern Nano-sizer or Zetasizer Nano range providing both exceptionally high performance and entry-level systems that incorporate combinations of particle size analyzer measurements was used. The surface functionality of the synthesized composite was studied by 
using Fourier transform infrared spectroscopy (FTIR) (Perkin Elmer) in the wavenumber range of $4000-400 \mathrm{~cm}^{-1}$ at a resolution of $4 \mathrm{~cm}^{-1}$. The size, shape, surface morphology, and elemental composition in dry powdered form were studied using field emission scanning electron microscopy coupled with energy dispersive X-ray (FESEM-EDX) (JEOL JSM 7600F). The Philips X-ray diffraction (XRD) instrument was used for understanding the crystal structure, and the samples were analyzed by placing the powder on a flat amorphous silica sample holder. The patterns were recorded in the $2 \theta$ range of 10-60 degrees at room temperature using $\mathrm{Cu} \mathrm{k} \alpha$ radiation $(\lambda=1.5418 \AA)$.

2.3. Synthesis of NiNPs. The NiNPs were synthesized from the nickel chloride-hydrazine $\left(\mathrm{NiCl}_{2}-\mathrm{N}_{2} \mathrm{H}_{4}\right)$ mixture in an aqueous sodium hydroxide $(\mathrm{NaOH})$ solution that was maintained at a high $\mathrm{pH} \sim 12.5$ [25]. The $\mathrm{N}_{2} \mathrm{H}_{4}$ in the alkaline $\mathrm{NaOH}$ solution is represented by the following oxidation reaction:

$$
\mathrm{N}_{2} \mathrm{H}_{4}+4 \mathrm{OH}^{-} \longrightarrow 4 \mathrm{e}^{-}+\mathrm{N}_{2}+4 \mathrm{H}_{2} \mathrm{O}, \quad \mathrm{E}^{\theta}=-0.16 \mathrm{~V}
$$

When the $\mathrm{Ni}$ ions from $\mathrm{NiCl}_{2}$ salt get mixed with $\mathrm{N}_{2} \mathrm{H}_{4}$ and $\mathrm{NaOH}$ hydroxide solutions, it consequently gets reduced $[26,27]$ :

$$
2 \mathrm{Ni}^{2+}+4 \mathrm{e}^{-} \longrightarrow 2 \mathrm{Ni}, \quad E^{\theta}=-0.25 \mathrm{~V}
$$

Therefore, precipitation of $\mathrm{Ni}$ with $\mathrm{N}_{2} \mathrm{H}_{4}$ behaving as a reductant in alkaline solution depends on $\mathrm{pH}$ of the solution which can be simply explained by the equation

$$
2 \mathrm{Ni}^{2+}+\mathrm{N}_{2} \mathrm{H}_{4}+4 \mathrm{OH}^{-} \longrightarrow 2 \mathrm{Ni}+\mathrm{N}_{2}+4 \mathrm{H}_{2} \mathrm{O}, \quad E^{\theta}=+0.09 \mathrm{~V}
$$

The discharge of NiNPs was enhanced by the addition of strong $\mathrm{NaOH}$ base which increased the solution $\mathrm{pH}$ and by constant maintenance of $\mathrm{Ni}$ ion concentration. Additionally, hydrazine in this reaction mixture acts as a surface ligand to the $\mathrm{Ni}$ particles by means of forming a stable complex in the $\mathrm{Ni}$ solution with respect to the molar ratio of $\mathrm{Ni}$ to $\mathrm{N}_{2} \mathrm{H}_{4}$. The colloidal synthesis offers a route for the synthesis of nanoparticles (NPs) with controlled size, composition, and structural features by taking advantage of the PVP molecules. In the present case, the NiNPs were added with equal amount of PVP molecules so that the surfaces of the NiNPs are protected as soon as they are formed from the agglomeration where the PVP serves as the surface stabilizer, growth modifier, dispersant, and also reducing agent. The PVP molecules show a high degree of compatibility both in solution and in film form, with most of the inorganic salt solutions. The PVP is widely used in a broad variety of industries due to its unique physicochemical properties, offering good solubility in water and many organic solvents where its chemical is stable and providing affinity towards complex hydrophobic and hydrophilic substances with nontoxic character.
2.4. Synthesis of Amine-Functionalized NiNPs. For the amine functionalization of earlier formed PVP-NiNPs, we have used the cocondensation method by the incorporation of APTES. In brief, about $0.5 \mathrm{~g}$ of PVP-NiNPs was dispersed in $50 \mathrm{~mL}$ DMSO under sonication for about $1 \mathrm{~h}$, and after the period, the mixture was transferred to a round bottom flask connected to a reflux condenser maintained at inert atmosphere. About $400 \mu \mathrm{L}$ of 3-APTES was added to this mixture, refluxed at $120^{\circ} \mathrm{C}$ for at least $3 \mathrm{~h}$, and after the completion of reaction, the resulting solution was cooled to room temperature. The solution was added with ethanol (degassed), separating the precipitate by means of centrifugation at $12000 \mathrm{rpm}$ for about $15 \mathrm{~min}$, and this washing process with ethanol was continued several times so as to completely remove the unreacted 3-APTES and any other unwanted byproducts. Finally, the amine functionalized NiNPs (APTES-NiNPs) were formed by drying the product at $60^{\circ} \mathrm{C}$ overnight.

2.5. Real Sample Extraction. For the real sample extraction, we have employed the same method as described by Moors and Massart [28] with little modifications. Briefly, about $30 \mathrm{~mL}$ raw milk was spiked with a known Penicillin G concentration, vortexed for $2 \mathrm{~min}$ at room temperature so as to allow for the equilibration of $\beta$-lactams with that of milk matrix before their actual extraction. Now, the contents were subjected to centrifugation at $3000 \mathrm{rpm}$ for $10 \mathrm{~min}$, and then, $10 \mathrm{~mL}$ of defatted milk was deproteinized by the addition of $10 \mathrm{~mL}$ of acetonitrile in a dropwise manner with continuous vortex so as to allow for the complete mixing and centrifuged again at $4000 \mathrm{rpm}$ for $15 \mathrm{~min}$. Following the centrifugation, $10 \mathrm{~mL}$ of supernatant was transferred to a beaker, heated to $60^{\circ} \mathrm{C}$ in order to evaporate the added acetonitrile, and the heating was continued until the volume reduces approximately to $1 \mathrm{~mL}$. Then, $1 \mathrm{~mL}$ of PBS was added immediately so as to avoid the degradation of analyte, the mixture was centrifuged at $4000 \mathrm{rpm}$ for $20 \mathrm{~min}$, and the supernatant was collected and filtered through a $0.22 \mu \mathrm{m}$ filter paper and used further for the analysis.

2.6. Analytical Procedure. For the detection of Penicillin G, the oxidation peak current was measured, and for that, the voltammetric response in the potential range of $-0.6-0.6 \mathrm{~V}$, $0.1 \mathrm{M}$ PBS (pH 7.0), as the supporting electrolyte was applied. The differential pulse voltammetry (DPV) was performed by applying $-0.4 \mathrm{~V}$ accumulation potential for about $180 \mathrm{sec}$ and equilibrium time of $10 \mathrm{sec}$. For each voltammogram measurement, a scan rate of $0.1 \mathrm{~V} / \mathrm{s}$ was applied and was conducted at room temperature $\left(25^{\circ} \mathrm{C}\right)$ only.

\section{Results and Discussion}

The dynamic light scattering studies using the Zetasizer nanoseries were performed for measuring the size of particles in the solution phase, and for that, the colloidal solutions of NiNPs settled at the bottom side of the flask during the chemical synthesis before the drying was taken. The zeta potential analysis of NiNPs formed by the wet chemical method provided the information that the hydrodynamic 
size of particles is about $15 \mathrm{~nm}$ (data not shown here). The obtained size is the combination of NiNP core along with the APTES-coated material and a little portion of the solvent layer attached to the surface as the particles move under the influence of Brownian movement. Following the zeta potential studies, the particle size and surface morphology of synthesized NPs were determined by FESEM; Figures 2(a) and 2(b) shows the FESEM and EDX images of NiNPs (APTES coated) produced by the simplified chemical reduction method. It is indicated from the FESEM image (Figure 2(a)) that the NiNPs are of spherical shape having the rough surface and the particles are within the instrument's range of size detection, as the particles are formed in the nanometer size (scale of $500 \mathrm{~nm}$ was used). Further, the results of the EDX spectroscopic detector connected to the FESEM instrument used for the investigation of elemental composition in the synthesized NiNPs (Figure 2(b)) confirmed the presence of corresponding elements. The NiNP spectrum displayed the eminent peaks of Ni; the NPs are coated with gold during the sample preparation, while the presence of oxygen can be from the APTES and surface oxidation of the particles [29]. Thus, from the analysis, the availability of $\mathrm{Ni}$ in the NiNPs can aid for the catalytic property of the modified electrode.

The powdered XRD analysis was used for the investigation of the crystal structure and phase of NiNPs at different stages of their synthesis. Figures 3(a) and 3(b) show the comparison of the XRD patterns of PVP-NiNPs and NiNPs (modified with APTES), respectively. From Figure 3(a), the chemically synthesized NiNPs showed diffraction peaks at $2 \theta$ angle of $44.5^{\circ}, 51.94^{\circ}$, and $76.42^{\circ}$, corresponding to crystal planes of 111,200 , and 220, respectively. Similarly, the broad peak around $25^{\circ}$ corresponds to the PVP molecules that were used for the surface coating of NiNPs. The pattern shows a cubic structure of the sample with a single phase, and in addition, the observation of scattered peaks indicates the existence of particles in the nanosize range. Similar to Figure 3(a), the maximum intensity peak (111) in Figure 3(b) was used to estimate the crystalline size and was found to be $15 \mathrm{~nm}$ using the Scherrer equation. The shape of Ni-bound polymer particles is spherical as confirmed by the FESEM image (Figure 2(a)), and the particles are linked together with the help of APTES molecules to form chains; the XRD peak information shown in Figure 3(b) confirms the formation of NiNPs (having APTES groups at the surface) and that too in a face-centered cubical structure. The observation of NiNP peak positions both in the PVPNiNPs and NiNPs confirms the existence of NiNPs in both the composites and is also in accordance with the JCPDS (Joint Committee on Power Diffraction Standards). Therefore, the XRD pattern noteworthily supports for formation of NiNPs:

$$
D=\frac{k \lambda}{\beta \cos \theta},
$$

where $D$ is the particle diameter, $k$ is a constant that equals to $0 \cdot 89, \lambda$ is the $\mathrm{X}$-ray wavelength $(0.134065 \mathrm{~nm})$, $\beta$ is the full wavelength at half maximum, and $\theta$ is the half diffraction angle.

Figure 4 shows the FTIR spectrum of NiNPs at room temperature where the spectrum was recorded in the wavenumber range of $4000-400 \mathrm{~cm}^{-1}$. The FTIR spectrum shows characteristic absorption bands at 3212, 1623, 1402, and $1077 \mathrm{~cm}^{-1}$ which can be corresponding to the $\mathrm{O}-\mathrm{H}$ stretching frequency from the $\mathrm{Ni}(\mathrm{OH})_{2}$ groups, and the band around 1623 suggests for the $\mathrm{C}=\mathrm{O}$ group, while $1077 \mathrm{~cm}^{-1}$ band reveals for the $\mathrm{N}-\mathrm{H}$ stretching frequency from APTES, respectively [30].

Figures 5(a)-5(d) show electrochemical behaviors of penicillin at the surface of the electrode and the observation of weak reversible redox peaks at the surface of bare SPCE (Figure 5(a)), indicating the slow-moving electron transfer property of electrode and lower accumulation of penicillin on it which is a result of the low surface area. The sensitivity of redox peaks enhanced dramatically when we used the SPCE's surface modified with the NiNPs (Figure 5(c)). The increased peak current following the SPCE modification with NiNPs is due to an enhancement in the surface area and electron transfer rate of SPCE, and all are associated with the inbuilt conductive properties of $\mathrm{Ni}$. In general, the potential of the developed sensor depends on various factors such as effect of supporting electrolytes and redox indicators, accumulation potential and time, selectivity, sensitivity, range of linear responses, and detection limits. The figure indicates CVs of modified and unmodified SPCE in the electrolyte solutions of $0.1 \mathrm{mM} \mathrm{K}_{3} \mathrm{Fe}(\mathrm{CN})_{6}$ and $0.1 \mathrm{M} \mathrm{HCl}$, with redox peaks in the potential range of -0.6 to $+0.6 \mathrm{~V}$. The bare SPCE results show lower peak current, and this was increased from 0.15 to $20 \mu \mathrm{A}$ when we incorporated the NiNPs to modify the electrode surface. For the NiNPs/SPCE, the highest current of $20 \mu \mathrm{A}$ was observed, and this peak current is directly proportional to the square root of the scan rate, which suggests that the process is controlled by diffusion [31].

Further, to test the efficiency of NiNPs for sensors, the active surface area of bare and NiNP-modified SPCE was calculated at the CVs recorded from $1 \mathrm{mM} \mathrm{K}_{3} \mathrm{Fe}(\mathrm{CN})_{6}$ containing $50 \mathrm{mM} \mathrm{KCl}$ solution at different scan rates (10$100 \mathrm{mV} / \mathrm{s}$ ), and for that, the Randles-Sevcik formula shown below [32] was used. From the analysis, the bare SPCE was found to maintain the active surface area of $0.034 \mathrm{~cm}^{2}$ while the NiNP-modified electrode has an increase in the active surface area to be $0.084 \mathrm{~cm}^{2}$. This confirms that the increase in the active surface area of the SPCE following the modification with that of the NiNPs [33]:

$$
\text { Aeff }=\frac{\text { Slope }}{2.69 \times 10^{5} n^{3 / 2} D^{1 / 2} C} \text {, }
$$

where $n$ is the number of electrons participating in the redox reaction, $A$ is the surface area of the electrode $\left(\mathrm{cm}^{2}\right), D$ stands for the diffusion coefficient of molecules in solution $\left(7.6 \times 10^{-6} \mathrm{~cm}^{2} \mathrm{~s}^{-1}\right)$, and $C$ is the concentration of $\mathrm{K}_{3} \mathrm{Fe}(\mathrm{CN})_{6}(\mathrm{M}) . v$ is the scan rate $\left(\mathrm{Vs}^{-1}\right)$, from the slope of plot of $I_{\mathrm{pc}}$ vs. $v^{1 / 2}$.

As shown in Figure 5(b), the anodic current increases from bare SPCE to modified NiNPs on the surface which 


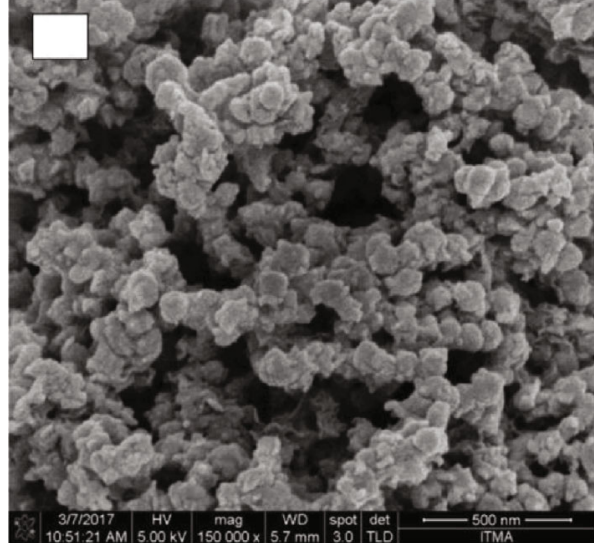

(a)

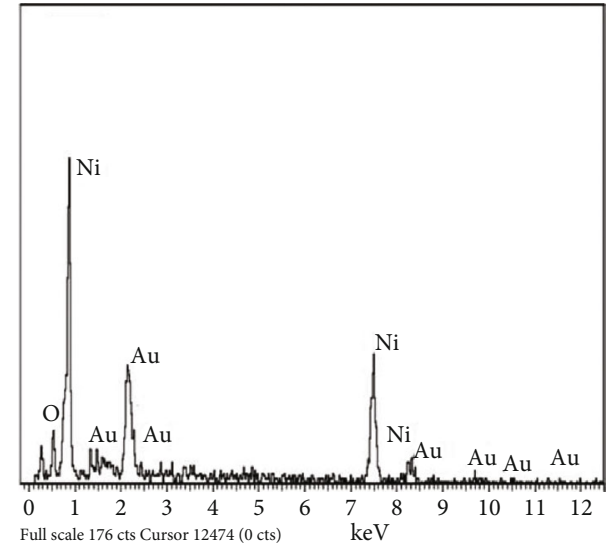

(b)

Figure 2: The FESEM and EDX of NiNPs.

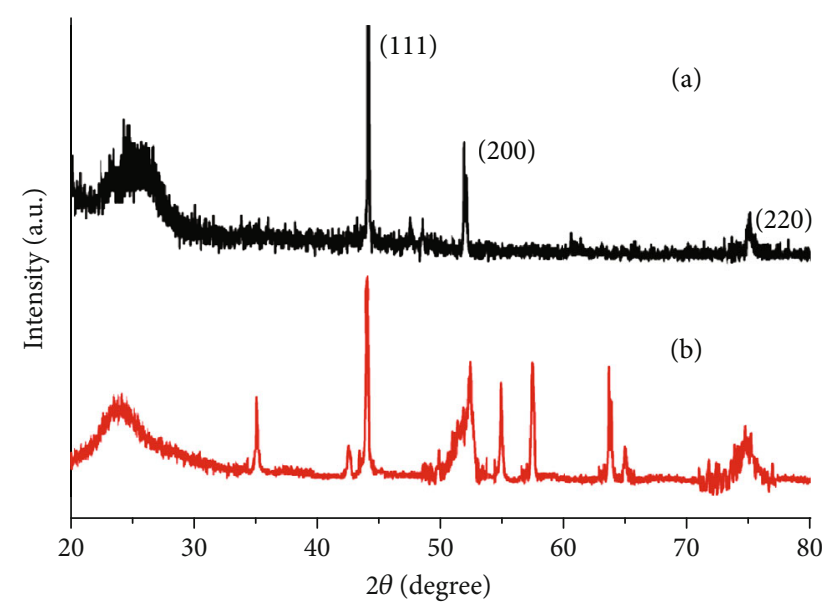

FIGURE 3: Powdered XRD patterns of (a) PVP-NiNPs and (b) chemically synthesized NiNPs.

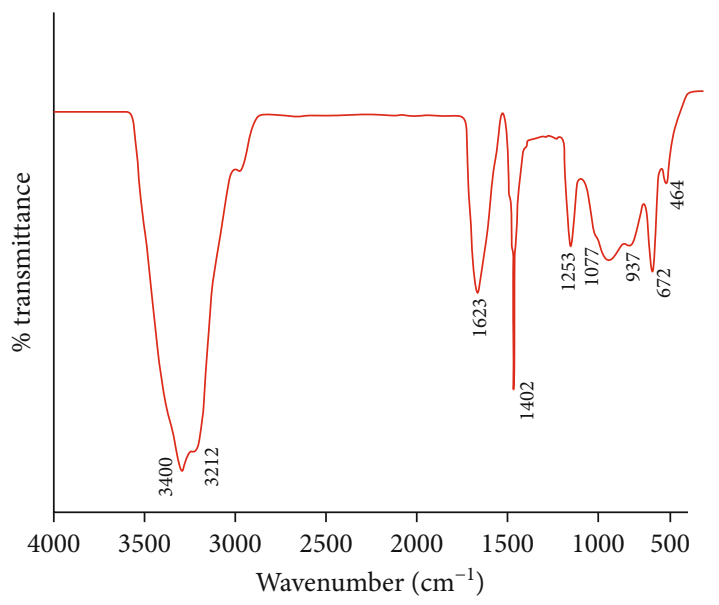

FIGURE 4: FTIR spectrum of the synthesized NiNPs.

suggest that the modifying materials were successfully deposited on the surface of the SPCE. From the figure, the observation of well-defined peaks at the bare electrode surface confirms the occurrence of redox reactions with anodic $\left(E_{\mathrm{pa}}\right)$ and cathodic $\left(E_{\mathrm{pc}}\right)$ peak potentials around $-0.05 \mathrm{~V}$ and $+0.3 \mathrm{~V}$, respectively, and is for the redox behavior of both $\mathrm{Fe}(\mathrm{CN})_{6}{ }^{3-}$ and NiNPs. The deposition of NiNPs onto the surface of NiNPs/SPCE induced a large reduction peak current compared with bare SPCE. There is migration of electron to the electrode and acceptance, which led to the reduction of the oxidation number from +3 to +2 . The reverse process known as oxidation is possible by losing one electron to form $3+$.

\subsection{Optimization of Parameters Using CV}

3.1.1. Effect of Supporting Electrolyte. The effects of a supporting electrolyte play a vital role in electrochemical detection of analytes. The solutions were prepared with the same concentration $(0.1 \mathrm{M})$ and $\mathrm{pH}$ and were used to investigate the oxidation of $10 \mu \mathrm{M}$ antibiotics at the surface of NiNPs/SPCE. In this study, four different buffers such as (1) PBS, a mixture of monosodium dihydrogen phosphate and disodium hydrogen phosphate; (2) acetate buffer, a mixture of sodium acetate and acetic acid; (3) citrate buffer, a mixture of sodium citrate and citric acid; and (4) Britton Robinson buffer, a mixture of acetic, boric, and phosphoric acids of equal strengths (0.1 M, pH5) were investigated; Figure 6 shows the results of influence of each buffer solution towards voltammetric oxidation of $10 \mu \mathrm{M}$ Penicillin G. It was observed from the results that among various supporting electrolytes used for investigating voltammetric oxidation of Penicillin G at NiNPs, best results with respect to shape and sensitivity are obtained for the PBS (Figure 6(b)) with peak current of $13.1 \mu \mathrm{A}$; therefore, PBS was selected for detection of Penicillin G.

3.1.2. Effect of $p H$. The investigation of the effect of supporting electrolyte $\mathrm{pH}$ provided the information that both the peak potential and peak current directly depend on $\mathrm{pH}$ of buffer solution. The results of voltammetric response of $10 \mu \mathrm{M}$ Penicillin $\mathrm{G}$ at different $\mathrm{pH}(2-10)$ are presented in Figure 7. It was observed from the analysis that the oxidation of Penicillin $\mathrm{G}$ in all $\mathrm{pH}$ ranges displayed voltammetric 


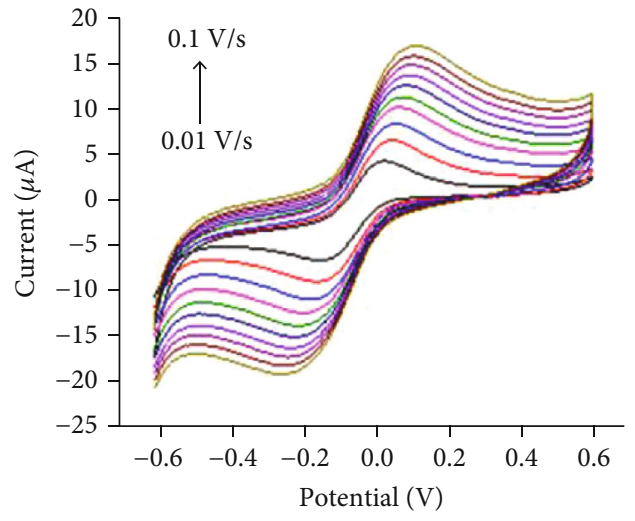

(a)

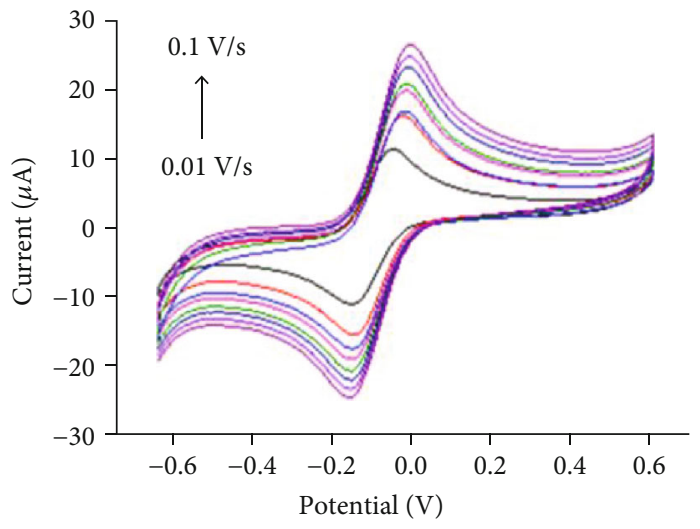

(c)

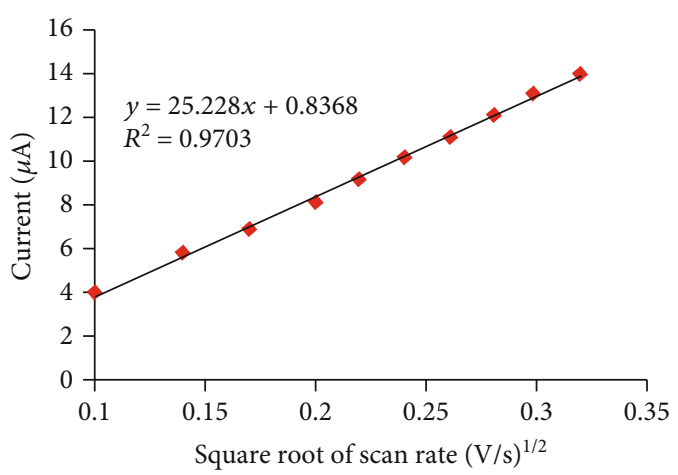

(b)

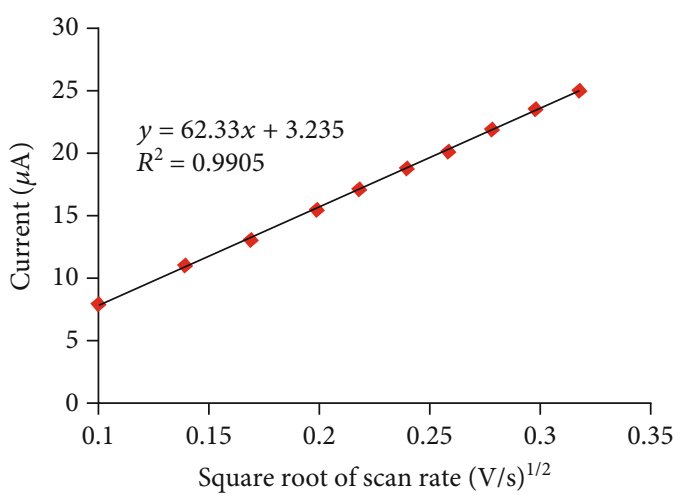

(d)

Figure 5: CVs of bare SPCE (a) and NiNPs/SPCE (c) in $1.0 \mathrm{mM} \mathrm{K}_{3} \mathrm{Fe}(\mathrm{CN})_{6}$ and $0.1 \mathrm{M} \mathrm{KCl}$. (b, d) corresponds to the respective plots of peak currents $(\mu \mathrm{A})$ against the square root of scan rate $(\mathrm{V} / \mathrm{s})^{1 / 2}(0.01,0.02,0.03,0.04,0.05,0.06,0.07,0.08,0.09$, and $0.1 \mathrm{~V} / \mathrm{s})$.

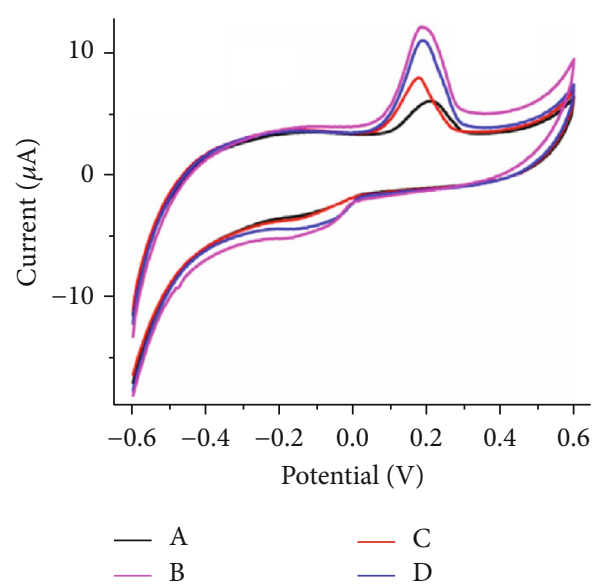

(a)

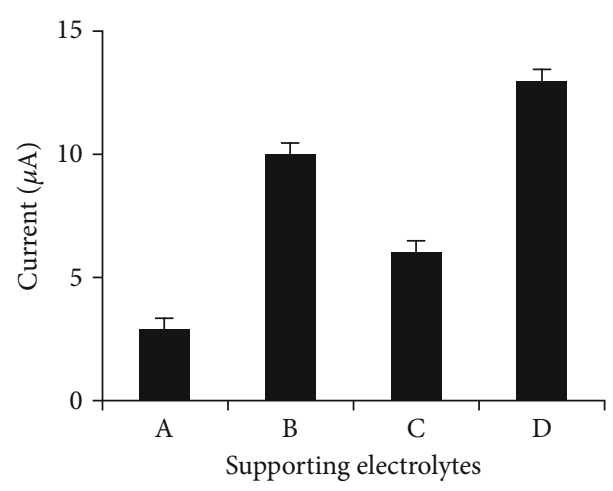

(b)

Figure 6: (a) CV studies and (b) effect of supporting electrolytes on voltammetric oxidation of $10 \mu \mathrm{M}$ Penicillin G in 0.1 M, pH 4.0: (A) acetate buffer, (B) Britton Robinson buffer, (C) citrate buffer, and (D) PBS.

signals to some extent. From the results, we see an improvement in the peak current with an increased $\mathrm{pH}$ because of the deprotonation or loss of electron [34]. The observation of a relatively lower oxidation current in the strong acidic medium can be correlated with the fact that the amino groups of Penicillin G molecule get protonated to form some cationic species first. This protonated amine group further forms a zwitterionic species with that of the spatial carboxylic group of Penicillin G; by doing so, there is a decreased interaction with the NiNP electrode and limited oxidation of Penicillin $\mathrm{G}$ at lower $\mathrm{pH}$. With a slight increase in $\mathrm{pH}$ towards neutral medium, an enhancement in the signal is 


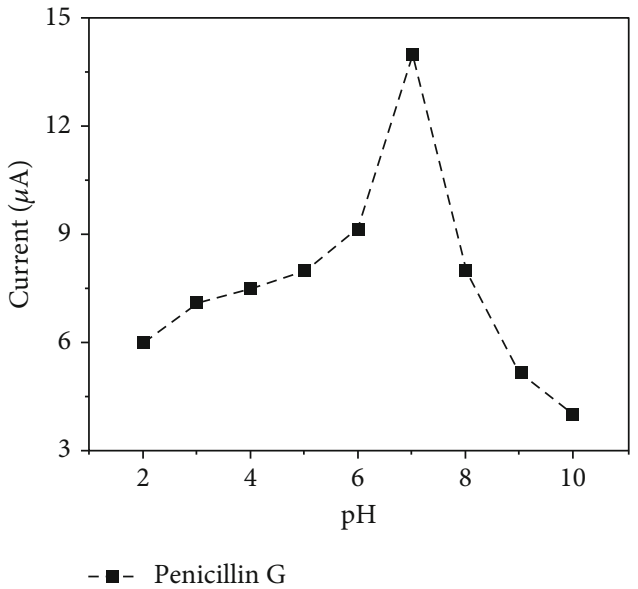

Figure 7: Effect of $\mathrm{pH}$ on voltammetric oxidation of Penicillin $\mathrm{G}$ at NiNPs/SPCE.

observed which can be attributed to a better interaction between analyte and electrode corresponding to the fact of deprotonation of the amino group and no such zwitterion formation with the carboxylic group of Penicillin G, and all supported for enhanced oxidation and associated current increase. With further increase of $\mathrm{pH}$ towards more basic conditions, we observed a decreased oxidation current, and this can be attributed to the formation of zwitterion species again by the migration of proton intramolecularly from the amino group to the carboxylic group of Penicillin G. Under basic conditions, a greater number of free $\mathrm{OH}^{-}$ are available and they can readily grab the proton from the acidic group of Penicillin $\mathrm{G}$ to form $\mathrm{COO}^{-}$which rapidly forms zwitterion by taking proton from the amine group, and this process occurs reversibly that finally reduces the oxidation. Thus, the best results with respect to sensitivity and shape of voltammogram is obtained at $\mathrm{pH} 7.0$ with peak current of $14 \mu \mathrm{A}$ for Penicillin G. Therefore, 0.1 M PBS of $\mathrm{pH} 7.0$ was chosen as optimum medium for voltammetric oxidation of Penicillin G at NiNPs/SPCE. The observation of PBS of $\mathrm{pH} 7.0$ as the optimum condition for the voltammetric oxidation of Penicillin $\mathrm{G}$ is in close conformity with the previous report by [35].

3.1.3. Effect of Accumulation Time of Penicillin G. Accumulation time $\left(t_{\text {acc }}\right)$ is the specific time taken for the analyte to be adsorbed onto the surface of the electrode, and in a similar way, the accumulation time for the adsorption of Penicillin $\mathrm{G}(10 \mu \mathrm{M})$ onto the NiNPs/SPCE electrode is shown in Figure 8. For the analysis, the oxidative response of Penicillin $\mathrm{G}$ in connection with the accumulation time was investigated using the CV measurements. From the analysis of results, it can be observed that the peak current is getting increased with an increase in the $t_{\text {acc }}$ value over the range of 30$180 \mathrm{sec}$ due to the rapid adsorption of Penicillin $\mathrm{G}$ analyte onto the surface of SPCE/NiNPs. We observed that the highest value of peak current of $14.8 \mu \mathrm{A}$ at the $t_{\mathrm{acc}}$ of $180 \mathrm{sec}$ became almost leveled off, and further increase of $t_{\text {acc }}$ beyond $180 \mathrm{sec}$ did not bring much change to the peak current value. Similar observations were reported by $\mathrm{Ma}$ et al. [36] where

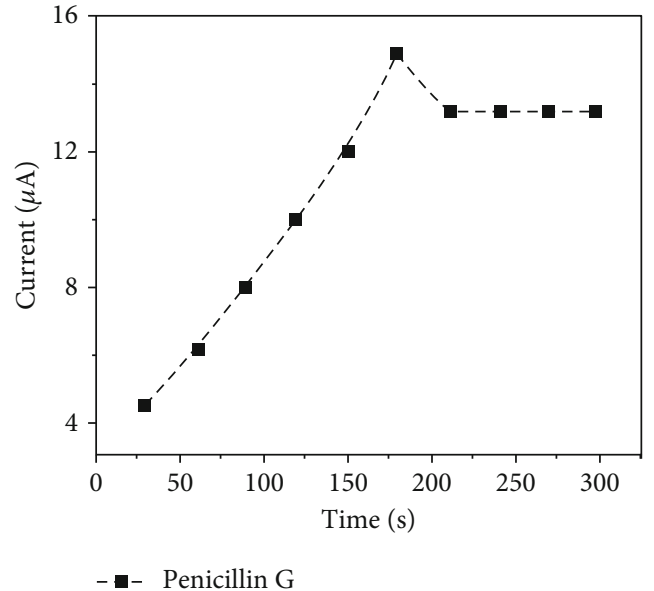

FIGURE 8: Influence of accumulation time on the oxidation peak currents of Penicillin $\mathrm{G}(10 \mu \mathrm{M})$ at the surface of NiNPs/SPCE in PBS.

the levelling off for the current can be attributed to the saturation of analytes onto the surface of the electrode and in our case, the saturation of Penicillin G analyte onto the SPCE/NiNP electrode. Thus, the accumulation time of $180 \mathrm{sec}$ was chosen as the optimum value for the following analyses.

3.1.4. Effect of Accumulation Potential. The accumulation potential in general is the electrostatic potential that is maintained at the shear plane of the electrode surface and is mostly influenced by the surface charge and local environment of the electrode material. The results of the study of accumulation potentials on the oxidation of Penicillin G indicates that by varying the potential from -0.6 to $0.4 \mathrm{~V}$ as shown in Figure 9, there is an increase in the current first, and with further increase of potential, we observed a fall in the current for the Penicillin G detection. The current increased from 2.1 to $14.8 \mu \mathrm{A}$ when we varied the potential from 0.2 to $-0.6 \mathrm{~V}$ because of the fact that the reduced form of penicillin molecules has more absorptivity on the surface of the modified electrode. However, at the negative potentials lower than $-0.4 \mathrm{~V}$, we observed a decrease in the peak current due to the thick layer of analyte on the surface of SPCE with the evolution of hydrogen bubbles which have the ability to decrease the sensitivity of the electrode or even damage it. Based on the overall analysis, the optimum accumulation potential for the voltammetric oxidation of Penicillin $G$ at the surface of NiNPs was considered as $-0.4 \mathrm{~V}(35 \mu \mathrm{A})$.

3.1.5. Effect of NiNP Amount. The effect of the amount of NiNPs on peak current was evaluated and is shown in Figure 10. As shown in Figure 10, the results of the effect of the NiNP amount indicate an increase in the volume of nanocomposite of Penicillin $\mathrm{G}$ from 1 to $10 \mu \mathrm{L}$, and the peak current increased steadily until it reaches $5 \mu \mathrm{L}$ with peak current of $15.1 \mu \mathrm{A}$. But as volume exceeded $5 \mu \mathrm{L}$, the peak current decreased steadily to $2.1 \mu \mathrm{A}$ for Penicillin G. The observation of such decreased conductivity effect can be linked to an increase in the thickness of the nanocomposite at the electrode surface where it blocks the free movement 


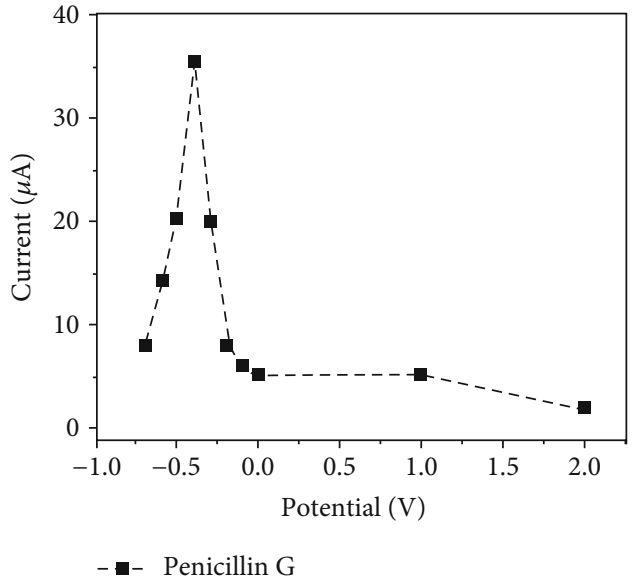

Figure 9: Effects of accumulation potential on the oxidation peak current of Penicillin G in $10 \mu \mathrm{M}$ on the surface of NiNPs/SPCE in PBS ( $\mathrm{pH} 7.0)$.

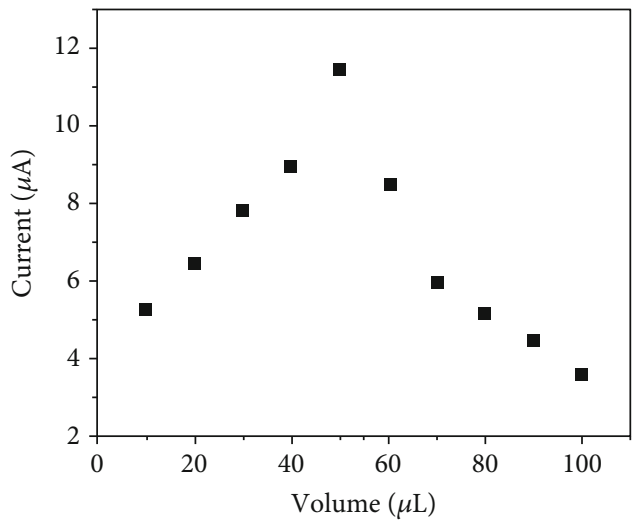

FIGURE 10: Effect of amount of NiNPs on the voltammetric response of $10 \mu \mathrm{M}$ Penicillin G in PBS ( $\mathrm{pH} 7.0$ ); scan rate $50 \mathrm{mV} / \mathrm{s}$.

of electrons [37]. Based on this, the $5 \mu \mathrm{L}$ volume was selected as the optimum amount of nanocomposite which was used for the fabrication of NiNPs/SPCE.

3.1.6. Effect of Scan Rate. The influence of scan rates was studied in the range of $10-100 \mathrm{mVs}^{-1}$. The relationship between oxidation peak currents of analytes and scan rates was investigated so as to ascertain their electrochemical mechanism at NiNPs. Figure 11 shows the $\mathrm{CV}$ of $10 \mu \mathrm{M}$ Penicillin $G$ on the electrode at different scan rates where the analysis of results established that an increase in the scan rate also increased the oxidation peak current of Penicillin G linearly and the peak potentials shifted to more positive potentials [38]. In addition, the increased oxidation peak current with respect to an increase in the scan rate provides the information that they both are in a linear relationship and is in accordance with the equation $I_{\mathrm{pa}}=513 v+2.404$; $R^{2}=0.9995$. From the equation, we observed the linear correlation to be 0.9995 , and this suggest that the NiNPmediated electrochemical oxidation of Penicillin $G$ is under

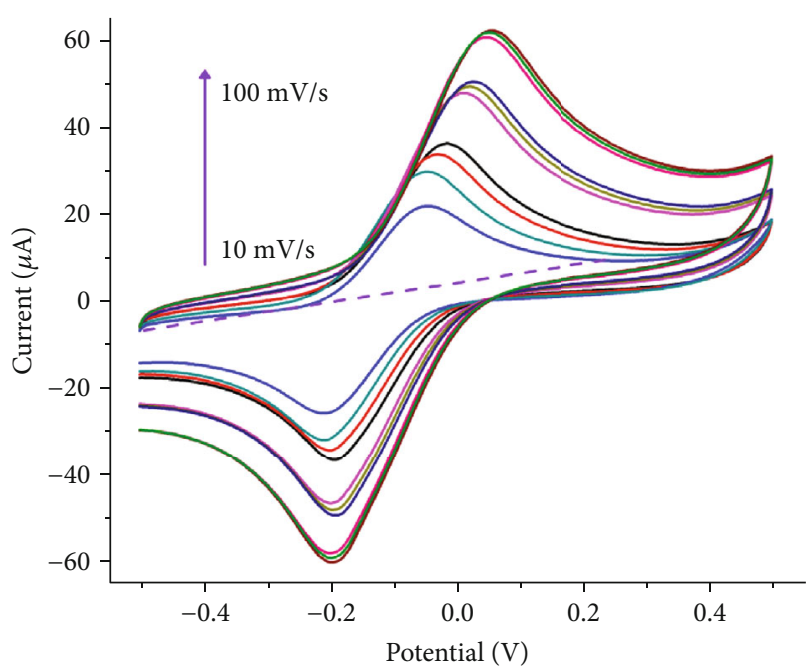

Figure 11: CVs for the oxidation of $10 \mu \mathrm{M}$ Penicillin $\mathrm{G}$ on the surface of NiNPs in PBS ( $\mathrm{pH} 7.0$ ); accumulation potential $-0.4 \mathrm{~V}$ and accumulation time $180 \mathrm{~s}$.

the adsorption control process. A plot of $\log I_{\mathrm{pa}}$ vs. $\log v$ also gives linear relationships that can be expressed as

$$
\begin{aligned}
\log \left(I_{\mathrm{pa}}\right)(\mu \mathrm{A}) & =0.745 \log v(\mathrm{mV} / \mathrm{s})-0.235, \\
R^{2} & =0.9982 .
\end{aligned}
$$

The plot has a slope of 0.745 with a correlation coefficient of 0.9982 , and this value is typical for the adsorption control process [39] and is further confirming the electrochemical oxidation of Penicillin $G$ at NiNPs under the adsorption control process.

Figure 12 shows the comparison of peak current against the changes in Penicillin G concentrations when the optimized experimental conditions were applied by making use of the DPV technique. It can be observed from the graph that there is a linear increase in the peak current with respect to the concentration in the range of $0.01-0.5 \mu \mathrm{M}$, meaning that a greater number of Penicillin $\mathrm{G}$ molecules are getting oxidized and further confirming the sensitivity of electrode material.

The changes in the concentration of penicillin against the current are compared and shown in Figure 13 where it signifies the linearity and slope of the graph plus the intercept of the plot. The DPV shown in Figure 13 clearly indicates that the plot of peak current $v s$. Penicillin G concentration is linear over $0.01-0.5 \mu \mathrm{M}$ of Penicillin $\mathrm{G}$ range, the linear regression equation being $I_{\mathrm{p}}(\mu \mathrm{A})=350.7491 C+1.0443$ Penicillin $\mathrm{G}$ and $R^{2}=0.9996$, where $C$ is $\mu \mathrm{M}$ concentration of Penicillin $\mathrm{G}$ and $I_{\mathrm{p}}$ is peak current. The limit of detection (LOD) and quantitation were determined at $0.01-0.5 \mu \mathrm{M}$ of Penicillin $\mathrm{G}$ according to definition of $Y_{\mathrm{LOD}}=Y_{B}+3 \sigma$ [40] which is found to be $0.00031 \mu \mathrm{M}$ and $0.0010 \mu \mathrm{M}$, respectively.

The reproducibility of the proposed sensor for the Penicillin G detection was evaluated by determining Penicillin $\mathrm{G}(10 \mu \mathrm{M})$ with seven different freshly prepared 


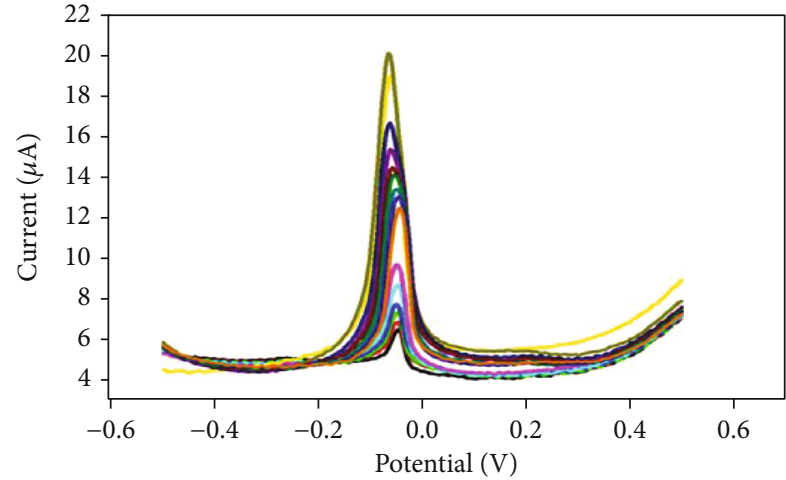

FIGURE 12: DPV for detection of Penicillin G on the surface of NiNPs/SPCE in PBS ( $\mathrm{pH} 7.0$ ); accumulation potential $-0.4 \mathrm{~V}$, accumulation time $180 \mathrm{sec}$.

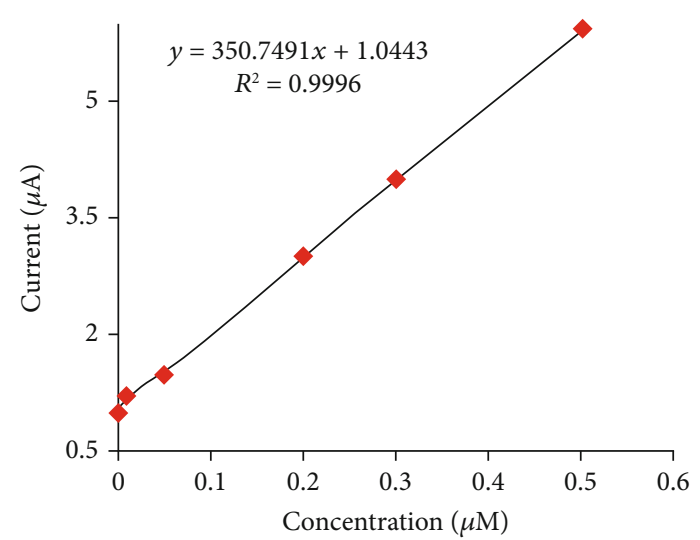

Figure 13: Calibration curve of peak current versus the concentration of penicillin under optimized experimental conditions.

electrodes. They were used to determine the oxidation anodic peak current, $I_{p a}$, of $10 \mu \mathrm{M}$ Penicillin G contained in $0.1 \mathrm{M}$ PBS with the aid of CV measurements. The results for reproducibility show response with relative standard deviations of $1.83 \%$ using the CV technique. The result indicates a satisfactory regeneration of the modification procedure in the preparation of NiNPs/SPCE. Thus, the reproducibility studies indicate that the NiNPs have better reproducibility and good stability and therefore can be used to determine the amount of Penicillin G.

Further, the interference study to check the influence of foreign species towards the detection of Penicillin G with the proposed method was investigated. For the investigation, we set the tolerance limit as the maximum concentration of foreign substance which caused not more than $\pm 5 \%$ relative error in the Penicillin G determination. The analysis was carried out by taking $10 \mu \mathrm{M}$ Penicillin $\mathrm{G}$ under the optimized conditions (PBS of $\mathrm{pH} 7.0$, accumulation potential $-0.4 \mathrm{~V}$, accumulation time $180 \mathrm{sec}$, and volume $5 \mu \mathrm{L}$ ), and $0.01 \mathrm{M}$ of various salts or ions (tetracycline, amoxicillin, vancomycin, $\mathrm{K}^{+}, \mathrm{Ca}^{2+}, \mathrm{Mg}^{2+}, \mathrm{Zn}^{2+}, \mathrm{Na}^{+}, \mathrm{Fe}^{2+}, \mathrm{Mn}^{2+}, \mathrm{SO}_{4}^{-2}, \mathrm{NO}_{3}^{-}$, $\mathrm{CO}_{3}{ }^{-2}$, and $\mathrm{Cl}^{-}$) was prepared. As mentioned earlier, the
TABle 1: Interference study for the determination of Penicillin G under the influence of other competitive ions or salts.

\begin{tabular}{lcc}
\hline Specie type & $\begin{array}{c}\text { Tolerance level } \\
(\mathrm{mM})\end{array}$ & $\begin{array}{c}\text { Signal change } \\
(\%)\end{array}$ \\
\hline Tetracycline & 50 & -4.46 \\
Amoxicillin & 50 & -4.02 \\
Vancomycin & 50 & -4.85 \\
$\mathrm{~K}^{+}, \mathrm{Ca}^{2+}, \mathrm{Mg}^{2+}, \mathrm{Zn}^{2+}, \mathrm{Na}^{+}$, & 200 & 3.0 \\
$\mathrm{Fe}^{2+}, \mathrm{Mn}^{2+}$ & 500 & 4.0 \\
$\mathrm{SO}_{4}^{-2}, \mathrm{NO}_{3}^{-}$ & 1000 & 5.0 \\
$\mathrm{CO}_{3}^{-2}, \mathrm{Cl}^{-}$ & & \\
\hline
\end{tabular}

tolerance limit is the change in the peak current height of less than $5 \%$ produced by the foreign species. The results mentioned in Table 1 indicated that interference species have less than 5\% peak currents in each analysis. In addition, Penicillin $G$ shows no interference with these salts or ions, thereby confirming the high selectivity of Penicillin G oxidation onto the prepared electrode material.

\section{Conclusion}

In conclusion, we provide here a novel NiNP composite for the electrochemical sensory detection of Penicillin G in the bovine milk samples in selective, sensitive, and economical means. The physical characterization of the composite confirmed the formation of particles in the nanometer size, and the presence of surface PVP and APTES groups served as the stabilizers and protection from self-oxidation. The use of this approach allowed for the detection limit and quantitation limit of Penicillin $\mathrm{G}$ to be a minimum of $0.00031 \mu \mathrm{M}$ and $0.0010 \mu \mathrm{M}$, respectively. In addition to the low detection levels, the composite also provided the good reproducibility, repeatability, and suitability, while simultaneously avoiding the interference of other common bovine milk containing residues like amoxicillin, tetracycline, and vancomycin. For the detection, the increased electrochemical performance of the SPCE can be attributed to the good electron transfer and enriched catalytic properties of the NiNPs in combination. Further, this technique can also be explored for costeffective and noninvasive detection of other antibiotic residues in the food and pharmaceutical samples.

\section{Data Availability}

The data used to support the findings of this study are available from the corresponding author upon request.

\section{Conflicts of Interest}

The authors declare no conflict of interest with the work and its findings.

\section{Acknowledgments}

The UPM authors acknowledge the Research grant No. 9443101 under Prof. Dr. Nor Azah Yusof, Department of 
Chemistry, Faculty of Science, Universiti Putra Malaysia, and extend their thanks to the Faculty of Science, Universiti Putra Malaysia. The King Saud University authors extend their appreciation to the Deanship of Scientific Research at King Saud University for funding the work through the research group project no. RG-148.

\section{References}

[1] M. D. H. Wirzal, A. R. M. Yusoff, J. Zima, and J. Barek, "Degradation of ampicillin and penicillin G using anodic oxidation," International Journal of Electrochemical Science, vol. 8, pp. 8978-8988, 2013.

[2] P. D. Anderson, V. J. D'Aco, P. Shanahan et al., "Screening analysis of human pharmaceutical compounds in U.S. surface waters," Environmental Science \& Technology, vol. 38, no. 3, pp. 838-849, 2004.

[3] M. Rabiet, A. Togola, F. Brissaud, J. L. Seidel, H. Budzinski, and F. Elbaz-Poulichet, "Consequences of treated water recycling as regards pharmaceuticals and drugs in surface and ground waters of a medium-sized Mediterranean catchment," Environmental Science \& Technology, vol. 40, no. 17, pp. 52825288, 2006.

[4] W. Du, H. Zhou, Z. Luo et al., "Selective determination of penicillin $G$ from tap water and milk samples using surface molecularly imprinted polymers as solid-phase extraction sorbent," Molecular Imprinting, vol. 2, no. 1, pp. 18-29, 2014.

[5] D. HELLER, M. SMITH, and O. CHIESA, "LC/MS/MS measurement of penicillin $\mathrm{G}$ in bovine plasma, urine, and biopsy samples taken from kidneys of standing animals," Journal of Chromatography B, vol. 830, no. 1, pp. 91-99, 2006.

[6] A. Junza, R. Amatya, D. Barrón, and J. Barbosa, "Comparative study of the LC-MS/MS and UPLC-MS/MS for the multiresidue analysis of quinolones, penicillins and cephalosporins in cow milk, and validation according to the regulation 2002/657/EC," Journal of Chromatography B, vol. 879, no. 25, pp. 2601-2610, 2011.

[7] M. Seifrtová, L. Nováková, C. Lino, A. Pena, and P. Solich, “An overview of analytical methodologies for the determination of antibiotics in environmental waters," Analytica Chimica Acta, vol. 649, no. 2, pp. 158-179, 2009.

[8] A. V. Herrera-Herrera, L. M. Ravelo-Pérez, J. HernándezBorges, M. M. Afonso, J. A. Palenzuela, and M. Á. Rodríguez-Delgado, "Oxidized multi-walled carbon nanotubes for the dispersive solid-phase extraction of quinolone antibiotics from water samples using capillary electrophoresis and large volume sample stacking with polarity switching," Journal of Chromatography A, vol. 1218, no. 31, pp. 53525361, 2011.

[9] S. Ge, W. Tang, R. Han et al., "Sensitive analysis of aminoglycoside antibiotics via hyphenation of transient moving substitution boundary with field-enhanced sample injection in capillary electrophoresis," Journal of Chromatography A, vol. 1295, pp. 128-135, 2013.

[10] P. Lacina, L. Mravcová, and M. Vávrová, “Application of comprehensive two-dimensional gas chromatography with mass spectrometric detection for the analysis of selected drug residues in wastewater and surface water," Journal of Environmental Sciences, vol. 25, no. 1, pp. 204-212, 2013.

[11] N. Migowska, M. Caban, P. Stepnowski, and J. Kumirska, "Simultaneous analysis of non-steroidal anti-inflammatory drugs and estrogenic hormones in water and wastewater sam- ples using gas chromatography-mass spectrometry and gas chromatography with electron capture detection," Science of the Total Environment, vol. 441, pp. 77-88, 2012.

[12] F. J. Lara, M. del Olmo-Iruela, C. Cruces-Blanco, C. Quesada-Molina, and A. M. García-Campaña, "Advances in the determination of $\beta$-lactam antibiotics by liquid chromatography," Trends in Analytical Chemistry, vol. 38, pp. 52-66, 2012.

[13] B. Le Bizec, G. Pinel, and J. P. Antignac, "Options for veterinary drug analysis using mass spectrometry," Journal of Chromatography A, vol. 1216, no. 46, pp. 8016-8034, 2009.

[14] E. S. Elmolla and M. Chaudhuri, "Degradation of amoxicillin, ampicillin and cloxacillin antibiotics in aqueous solution by the UV/ZnO photocatalytic process," Journal of Hazardous Materials, vol. 173, no. 1-3, pp. 445-449, 2010.

[15] E. Isarain-Chávez, R. M. Rodríguez, P. L. Cabot et al., "Degradation of pharmaceutical beta-blockers by electrochemical advanced oxidation processes using a flow plant with a solar compound parabolic collector," Water Research, vol. 45, no. 14, pp. 4119-4130, 2011.

[16] A. Dirany, I. Sirés, N. Oturan, and M. A. Oturan, "Electrochemical abatement of the antibiotic sulfamethoxazole from water," Chemosphere, vol. 81, no. 5, pp. 594-602, 2010.

[17] E. S. Elmolla and M. Chaudhuri, "Photocatalytic degradation of amoxicillin, ampicillin and cloxacillin antibiotics in aqueous solution using $\mathrm{UV} / \mathrm{TiO}_{2}$ and $\mathrm{UV} / \mathrm{H}_{2} \mathrm{O}_{2} / \mathrm{TiO}_{2}$ photocatalysis," Desalination, vol. 252, no. 1-3, pp. 46-52, 2010.

[18] M. Klavarioti, D. Mantzavinos, and D. Kassinos, "Removal of residual pharmaceuticals from aqueous systems by advanced oxidation processes," Environment International, vol. 35, no. 2, pp. 402-417, 2009.

[19] N. Sanvicens, I. Mannelli, J. P. Salvador, E. Valera, and M. P. Marco, "Biosensors for pharmaceuticals based on novel technology," Trends in Analytical Chemistry, vol. 30, no. 3, pp. 541-553, 2011.

[20] C. Cristea, M. Tertis, and R. Galatus, "Magnetic nanoparticles for antibiotics detection," Nanomaterials, vol. 7, no. 6, p. 119, 2017.

[21] P. de Lima-Neto, A. N. Correia, R. R. Portela, M. da Silva Julião, G. F. Linhares-Junior, and J. E. S. de Lima, "Square wave voltammetric determination of nitrofurantoin in pharmaceutical formulations on highly boron-doped diamond electrodes at different boron- doping contents," Talanta, vol. 80, no. 5, pp. 1730-1736, 2010.

[22] R. Gomes, "Determination of endocrine disrupters in sewage treatment and receiving waters," Trends in Analytical Chemistry, vol. 22, no. 10, pp. 697-707, 2003.

[23] M. Panizza and G. Cerisola, "Application of diamond electrodes to electrochemical processes," Electrochimica Acta, vol. 51, no. 2, pp. 191-199, 2005.

[24] N. W. Khun and E. Liu, "Linear sweep anodic stripping voltammetry of heavy metals from nitrogen doped tetrahedral amorphous carbon thin films," Electrochimica Acta, vol. 54, no. 10, pp. 2890-2898, 2009.

[25] P. N. Dave, P. N. Ram, and S. Chaturvedi, "Transition metal oxide nanoparticles: potential nano-modifier for rocket propellants," Particulate Science and Technology, vol. 34, no. 6, pp. 676-680, 2016.

[26] J. W. Park, E. H. Chae, S. H. Kim et al., "Preparation of fine Ni powders from nickel hydrazine complex," Materials Chemistry and Physics, vol. 97, no. 2-3, pp. 371-378, 2006. 
[27] T. Goto, Y. Ito, S. Yamada, H. Matsumoto, and H. Oka, "Highthroughput analysis of tetracycline and penicillin antibiotics in animal tissues using electrospray tandem mass spectrometry with selected reaction monitoring transition," Journal of Chromatography A, vol. 1100, no. 2, pp. 193-199, 2005.

[28] M. Moors and D. L. Massart, "Evaluation of solid-phase extraction of basic drugs from human milk," Journal of Pharmaceutical and Biomedical Analysis, vol. 9, no. 2, pp. 129-139, 1991.

[29] R. G. Chaudhary, J. A. Tanna, N. V. Gandhare, A. R. Rai, and H. D. Juneja, "Synthesis of nickel nanoparticles: microscopic investigation, an efficient catalyst and effective antibacterial activity," Advanced Materials Letters, vol. 6, no. 11, pp. 990998, 2015.

[30] S. Sudhasree, A. S. Banu, P. Brindha, and G. A. Kurian, "Synthesis of nickel nanoparticles by chemical and green route and their comparison in respect to biological effect and toxicity," Toxicological \& Environmental Chemistry, vol. 96, no. 5, pp. 743-754, 2014.

[31] H. Zhang, R. Xiao, B. Jin, D. Shen, R. Chen, and G. Xiao, "Catalytic fast pyrolysis of straw biomass in an internally interconnected fluidized bed to produce aromatics and olefins: effect of different catalysts," Bioresource Technology, vol. 137, pp. 82-87, 2013.

[32] J. Du, R. Yue, F. Ren et al., "Novel graphene flowers modified carbon fibers for simultaneous determination of ascorbic acid, dopamine and uric acid," Biosensors and Bioelectronics, vol. 53, pp. 220-224, 2014.

[33] L. Zhang, F. Zhang, X. Yang et al., "Porous 3D graphene-based bulk materials with exceptional high surface area and excellent conductivity for supercapacitors," Scientific Reports, vol. 3, no. 1 , article 1408, 2013.

[34] H. Bagheri, A. Afkhami, Y. Panahi, H. Khoshsafar, and A. Shirzadmehr, "Facile stripping voltammetric determination of haloperidol using a high performance magnetite/carbon nanotube paste electrode in pharmaceutical and biological samples," Materials Science and Engineering C, vol. 37, pp. 264-270, 2014.

[35] M. S. Ibrahim, D. A. Kulesh, S. S. Saleh et al., "Real-time PCR assay to detect smallpox virus," Journal of Clinical Microbiology, vol. 41, no. 8, pp. 3835-3839, 2003.

[36] X. Ma, J. Geiser-Lee, Y. Deng, and A. Kolmakov, "Interactions between engineered nanoparticles (ENPs) and plants: phytotoxicity, uptake and accumulation," Science of the Total Environment, vol. 408, no. 16, pp. 3053-3061, 2010.

[37] W. Li, X. Z. Tang, H. B. Zhang et al., "Simultaneous surface functionalization and reduction of graphene oxide with octadecylamine for electrically conductive polystyrene composites," Carbon, vol. 49, no. 14, pp. 4724-4730, 2011.

[38] A. Muhammad, R. Hajian, N. A. Yusof et al., "A screen printed carbon electrode modified with carbon nanotubes and gold nanoparticles as a sensitive electrochemical sensor for determination of thiamphenicol residue in milk," RSC Advances, vol. 8, no. 5, pp. 2714-2722, 2018.

[39] G. Singh, I. Y. Kim, K. S. Lakhi, P. Srivastava, R. Naidu, and A. Vinu, "Single step synthesis of activated biocarbons with a high surface area and their excellent $\mathrm{CO}_{2}$ adsorption capacity," Carbon, vol. 116, pp. 448-455, 2017.

[40] S. Cherian, R. K. Gupta, B. C. Mullin, and T. Thundat, "Detection of heavy metal ions using protein-functionalized microcantilever sensors," Biosensors and Bioelectronics, vol. 19, no. 5, pp. 411-416, 2003. 


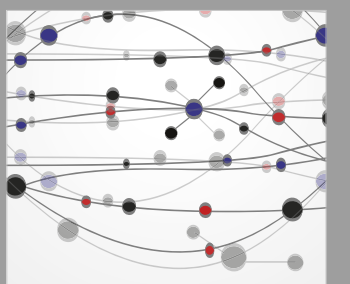

The Scientific World Journal
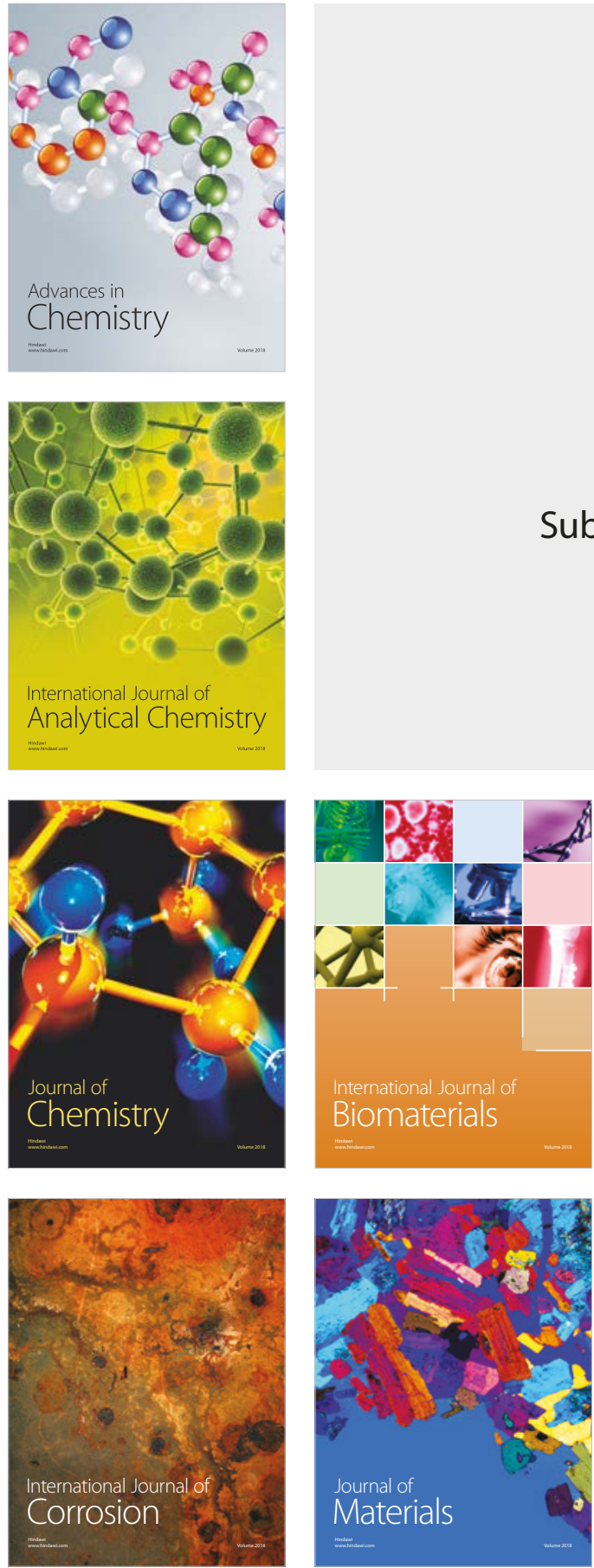

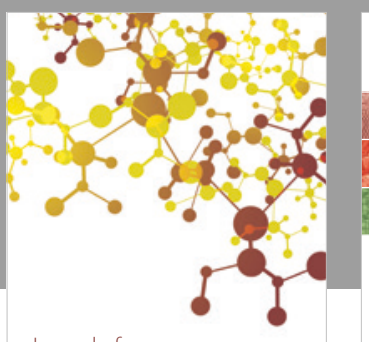

Journal of

Applied Chemistry
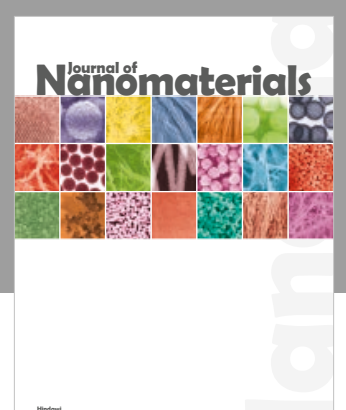

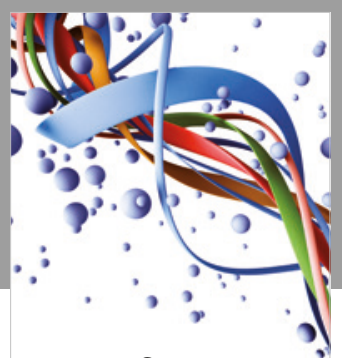

Scientifica

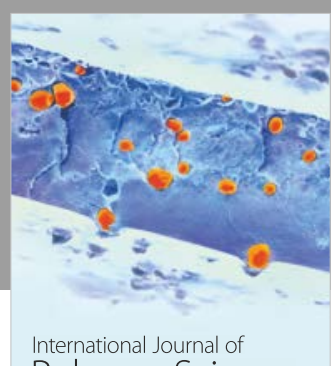

Polymer Science

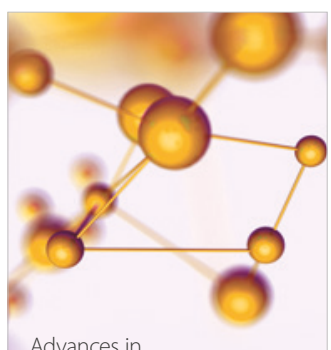

Physical Chemistry
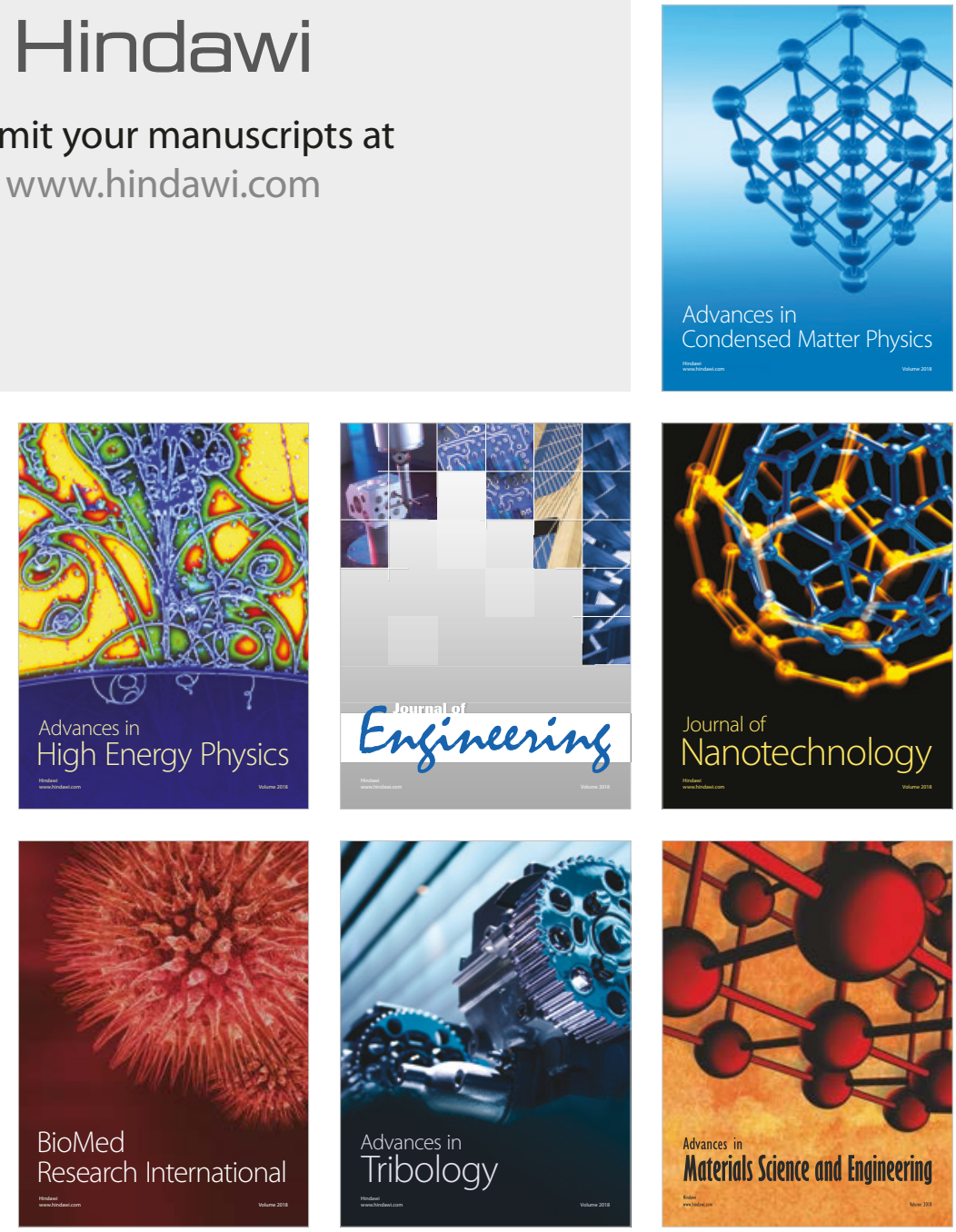